\title{
Is there any Need for Health Intervention on Pediculosis Capitis in Public Primary Schools in Kuantan, Pahang?
}

Muhammad Aqlan Mohd Zaki, Nor Faiza Mohd Tohit, Razman Mohd Rus

Department of Community Medicine, Kulliyyah of Medicine, International Islamic University Malaysia, Kuantan, Pahang, Malaysia.

Introduction: Pediculosis capitis among primary school children is a global problem which poses significant consequences among school children and caregivers alike. Previous studies showed an association between pediculosis capitis and sociodemographic factors such as school location, age, gender, ethnicity, parental education, monthly household income, number of siblings and number of family members. Primary schools in Malaysia consist of National School and National-type school (Chinese) and (Tamil), all of which have different sociodemographic backgrounds. Thus, this study aims to investigate and compare the prevalence of pediculosis capitis among children of different types of primary school in Kuantan to properly plan for future intervention. Materials and method: An analytical crosssectional study using stratified random sampling was carried out. The schools were stratified according to their types. Number of respondents from each school was determined by proportionate-to-size. Respondents from standard one to six were given self-administered validated questionnaire. Then, their hair and scalp were examined for the evidence of pediculosis capitis. Data was analysed using descriptive statistics. Results: There were 1,365 respondents involved in this study; consisting of students from National Schools $(n=791)$, Chinese Schools $(n=424)$ and Tamil Schools $(n=150)$. The overall median age was 8.0 years. Majority of them were males (53.41\%), of Malays ethnicity $(60.29 \%)$, with household income between RM1000-RM2999 (31.87\%) and from urban school location (98.68\%). The overall prevalence of pediculosis capitis was $9.6 \%(n=131)$. The prevalence of pediculosis capitis among the selected schools was found to be the highest in National-type school (Tamil) at 33.33\% $(n=50)$, followed by National School at 7.33\% $(n=58)$ and National-type school (Chinese) at 5.42\% ( $n=23)$. Conclusion: Pediculosis capitis showed an endemicity in all types of primary schools. Hence, preventive measures are necessary to reduce the transmission of head lice among school children. 